\title{
Synthesis and properties of fluorinated copolymerized polyimide films
}

\author{
Chuanhao Cao ${ }^{1}$ (D), Lizhu Liu ${ }^{1,2 *}$ Xinyu Ma', Xiaorui Zhang ${ }^{1,2}$ and Tong Lv ${ }^{1}$ \\ ${ }^{1}$ School of Materials Science and Engineering, Harbin University of Science and Technology, Harbin, China \\ ${ }^{2}$ Key Laboratory of Engineering Dielectric and Its Application, Harbin University of Science and \\ Technology, Ministry of Education, Harbin, China \\ *mrliu_hust@163.com
}

\begin{abstract}
Two series of fluorinated copolymerized polyimide films with different dianhydride ratios were prepared via the conventional two-step method by using 4,4-oxydianiline(ODA) as the diamine monomer, 4,4'-(hexafluoroisopropylidene) diphthalic anhydride(6FDA), 4,4'-oxydiphthalic anhydride(ODPA) and 3,3',4,4'- biphenyl tetracarboxylic dianhydride(BPDA) as the dianhydride monomer in N, N-dimethylacetamide. With the increase of 6FDA in the proportion of dianhydride, the tensile strength of the polyimide film showed a decreasing trend. This work provided a high performance film. The mass retention rate at $800^{\circ} \mathrm{C}$ was above $50 \%$. The glass transition temperatures of the two films were $260{ }^{\circ} \mathrm{C}$ and $275^{\circ} \mathrm{C}$. The storage modulus of the two were $1500 \mathrm{MPa}$ and $1250 \mathrm{MPa}$. The loss modulus were 218.70 MPa and 120.74 MPa. The transmittance of the film was $71.43 \%$. The transmittance of fluorinated copolymerized polyimide films were significantly improved in the visible region of ultraviolet light, indicating that the polyimide film with high transmittance, high tensile strength, high heat resistance and high storage modulus was successfully prepared. It had an excellent application prospect in the field of flexible display.
\end{abstract}

Keywords: fluoropolymers, polyimides, copolymerization, solubility, transparency.

How to cite: Cao, C., Liu, L., Ma, X., Zhang, X., \& Lv, T. (2020). Synthesis and properties of fluorinated copolymerized polyimide films. Polímeros: Ciência e Tecnologia, 30(2), e2020017. https://doi.org/10.1590/0104-1428.10019

\section{Introduction}

Polyimides were widely used in aerospace ${ }^{[1]}$, microelectronics ${ }^{[2]}$, national defense technology $\mathrm{y}^{[3]}$ and other fields ${ }^{[4]}$, due to its excellent thermal stability, mechanical properties, chemical stability and good dielectric properties ${ }^{[5-7]}$. Polyimide is one of the high performance polymers. However, the Kapton polyimide materials developed by DuPont Company have different defects, such as large structural rigidity, poor transmittance and high glass transition temperature, which leads to complicated subsequent processing ${ }^{[8-10]}$. Because of the close packing of polyimide chains and the strong transfer(CT) effect between molecules, the molecular chain has strong absorption and low transparency in the UV visible band, which restricts its application in the field of optical and photoelectron ${ }^{[11,12]}$.

The introduction of functional groups in diamine monomers or dianhydride monomers was currently the main method for preparing different kinds of polyimide materials ${ }^{[13-15]}$. Fluorinated polyimides were widely used in improving the transmittance of polyimide films. The introduction of fluorine group increases the free volume of the polyimide molecular chain, thereby improving the solubility, dielectric properties, etc ${ }^{[16,17]}$. In addition, the introduction of such groups could reduce the moisture absorption rate and increase the flame retardancy. The most important was that the fluorine-containing groups could weaken the intermolecular forces and increase the transparency.

But beyond that, another approached to achieving the desired material properties utilizes copolymerization. The third monomer was introduced into the molecular chain by a method of copolymerization, which changes the symmetry and regularity of the molecular chain, at the same time, the thermal stability of the polyimide film has not changed. This regularity could lead to a reduction in intermolecular interactions, which in turn results in new features, such as modified thermomechanical and gas permeation properties, and altered solubility. Furthermore, the properties of copolymer polyimides could be easily adjusted and controlled by varying the ratio of the dianhydride and diamine monomers.

The traditional aromatic benzene type PI was usually brownish yellow and the light transmittance was low, which was mainly due to the strong charge transfer complex (CTC) formed between aromatic dianhydride and aromatic diamine. Therefore, the surface of PI film has a certain orientation structure by introducing $\mathrm{F}$ group, lipid ring structure and so on into the Polyimide system.For example Xiao et al. ${ }^{[18]}$ researched the effects of the effect of the fluorine-containing group on the transmittance of the whole frequency band. 
Moon et al. ${ }^{[19]}$ had a transmittance of $60 \%$ at $400 \mathrm{~nm}$. Shen et al. ${ }^{[20]}$ added nano-silica particles in the F-containing system. Wu et al. added fillers to the polyimide film, which greatly improved the performance of the film ${ }^{[21,22]}$.

This article used 4,4-oxydianiline(ODA) as the diamine monomer, 4,4'-(hexafluoroisopropylidene) diphthalic anhydride(6FDA), 4,4'-oxydiphthalic anhydride(ODPA) and 3,3',4,4'- biphenyl tetracarboxylic dianhydride(BPDA) as the dianhydride monomer to synthesize two series of fluorinated copolymerized polyimide films with different proportions. The thermal properties, mechanical properties, solubility and optical properties of copolymer polyimide with different copolymerization ratios were investigated, and the polyimide with good thermal stability and light transmittance was developed, and its application field was expanded.

\section{Experiment}

\subsection{Experiment Materials}

For fabrication of fluorinated copolymerized polyimide films, the materials were listed in Table 1 .

\subsection{Experimental Procedure}

The polyamic acid (PAA) was prepared by solution polycondensation among ODA, 6FDA and ODPA/BPDA. The solid content in the PAA solution was $10 \mathrm{wt} \%$. The specific experimental steps were as follow: the solvent DMAc and the corresponding mass of ODA were added to the three-necked flask and stirred under nitrogen gas. After the ODA was completely dissolved, 6FDA and ODPA $\left(\mathrm{n}_{\mathrm{ODA}}: \mathrm{n}_{6 \mathrm{FDA} \& O D P A}=1: 1\right)$ or 6 FDA and BPDA $\left(\mathrm{n}_{\mathrm{ODA}}: \mathrm{n}_{6 \mathrm{FDA} \& \mathrm{BPDA}}=1: 1\right)$ were added in batches to three bottles until the "climbing-bar" phenomenon occurs and mechanically stirred at room temperature for $3 \mathrm{~h}$.

After cleaning the glass plate, the standing polyamic acid(PAA) was poured onto the glass plate and spread with scraper of a certain thickness. The film was put into oven, and the thermal imidization was carried out by gradient heating. Imidization process was $80{ }^{\circ} \mathrm{C} / 60 \mathrm{~min}$, $120^{\circ} \mathrm{C} / 30 \mathrm{~min}, 160^{\circ} \mathrm{C} / 30 \mathrm{~min}, 200^{\circ} \mathrm{C} / 30 \mathrm{~min}, 250^{\circ} \mathrm{C} / 30 \mathrm{~min}$, $300^{\circ} \mathrm{C} / 30 \mathrm{~min}, 350^{\circ} \mathrm{C} / 60 \mathrm{~min}$. When the temperature of the oven was cooled to room temperature, the polyimide films were obtained. The composition and name of the polyimide were shown in Table 2.

The reaction equation of ODA as diamine monomer, 6FDA and ODPA as dianhydride monomer was taken as an example. The reaction equation of the polymerization was shown in Figure 1.

\section{Measurement}

Fourier transform infrared (FTIR) spectra for fluorinated copolymerized polyimide films were measured in the range of 500-4000 $\mathrm{cm}^{-1}$ using the Bruker infrared spectrum analyzer EQUINOX55. In order to analyze the structural changes during the imidization process; The thermal stability of copolymerized polyimide films were recorded by using thermogravimetric analyzer(TGA), the residual mass was measured at a boost rate of $20{ }^{\circ} \mathrm{C} / \mathrm{min}$ under the nitrogen environment medium from $20^{\circ} \mathrm{C}$ to $800^{\circ} \mathrm{C}$; The storage modulus(E'), loss modulus(E”) and glass transition( $\mathrm{T}_{\mathrm{g}}$ ) of fluorinated copolymerized polyimide films with different dianhydride ratios were measured by dynamic thermal analyzer(DMA) Q800; The tensile strength of the copolymerized polyimide was measured by Shimadzu AGS-J electronic almighty material experiment machine, the standard of the sample was $100 \times 15 \mathrm{~mm}$ and the clamping distance was $100 \mathrm{~mm}$; Ultraviolet-visible (UV-vis) spectra of the polymer films were recorded on a Shimadzu UV-2450 instrument. It was intended to analyze the relationship between the transmittance of the films and the presence of different ratios of 6FDA and ODPA/BPDA.

\section{Results and Discussion}

\subsection{Structure characterization of fluorinated polyimide films}

The properties of polyimide were closely related to the degree of imidization during the preparation process. The current means of characterizing the degree of imidization include the deuteration method, the cyclization thermal effect method, and the nuclear magnetic resonance method, and the degree of imidization was calculated by measuring the moisture released during the cyclization. In this paper, the degree of imidization of polyimide films was qualitatively analyzed by infrared absorption spectroscopy.

The infrared spectra of fluorinated copolymerized polyimide films were shown in Figure 2. As could be seen from Figure 2, the absorption peaks of the above three locations disappeared, and it could be concluded that the amide structure have been reacted, and the structure of the prepared films were analyzed. It was found that the films had $-\mathrm{cm}^{-1}$ corresponded to the asymmetric expansion vibration of $\mathrm{C}=\mathrm{O}$, and the $1729 \mathrm{~cm}^{-1}$ corresponded to the $\mathrm{C}=\mathrm{O}$ symmetric expansion vibration. Compared with ordinary polyimide, we found that the carbonyl stretching vibrations on the fluorinated polyimide-imide rings moved toward higher wave numbers. It may be due to the inducing effect of trifluoromethyl group that made the carbonyl double bond enhance and the frequency of stretching vibration increase. $1500 \mathrm{~cm}^{-1}$ and $1050 \mathrm{~cm}^{-1}$ corresponded to the vibration of the benzene ring skeleton. The absorption

Table 1. Experiment Materials.

\begin{tabular}{ccc}
\hline Name & $\begin{array}{c}\text { Molecular } \\
\text { Formula }\end{array}$ & Source \\
\hline 4,4-oxydianiline(ODA) & $\mathrm{C}_{12} \mathrm{H}_{8} \mathrm{~N}_{2} \mathrm{O}$ & Sinopharm Group Chemical Reagent Co., Ltd. \\
4,4'-(hexafluoroisopropylidene) diphthalic anhydride(6FDA) & $\mathrm{C}_{19} \mathrm{H}_{6} \mathrm{~F}_{6} \mathrm{O}_{6}$ & Shanghai Macklin Biochemical Co.,Ltd. \\
4,4'-oxydiphthalic anhydride(ODPA) & $\mathrm{C}_{16} \mathrm{H}_{6} \mathrm{O}_{7}$ & Shanghai Macklin Biochemical Co.,Ltd. \\
3,3',4,4'- biphenyl tetracarboxylic dianhydride(BPDA) & $\mathrm{C}_{16} \mathrm{H}_{6} \mathrm{O}_{6}$ & Shanghai Macklin Biochemical Co.,Ltd. \\
\hline
\end{tabular}


peak at $1380 \mathrm{~cm}^{-1}$ represented the symmetric contraction vibration of the $\mathrm{C}-\mathrm{N}$, and the $725 \mathrm{~cm}^{-1}$ corresponded to the bending vibration of the $\mathrm{C}=\mathrm{O}$. These characteristic peaks were consistent with the standard peak positions of the polyimide in Table 2, indicating the presence of polyimide structure and characterizing the polyimide structure.

\subsection{Thermal stability of fluorinated polyimide films}

Figure 3 displayed the thermogravimetric curves of fluorinated copolymerized polyimide films with different proportions of dianhydride.

From Figure $3 \mathrm{a}$, it could be seen that the copolymerized polyimide began to decompose at $500{ }^{\circ} \mathrm{C}$, and the weight loss at $5 \%$ was $533.7,550.31,546.4,557.8$, and $560.7^{\circ} \mathrm{C}$, respectively. With the increase of 6FDA content in dianhydride, the initial decomposition temperature of the polyimide film also increased slightly. This was mainly due to the presence of $\mathrm{C}-\mathrm{F}$ bond in the fluorinated polyimide polymer. The $\mathrm{C}-\mathrm{F}$ bond energy was as high as $486 \mathrm{~kJ} / \mathrm{mol}$, which required a large amount of heat for thermal decomposition to break it, so it had a high initial thermal decomposition temperature. Figure $3 b$ had the same principle. The temperature of polyimide film weightlessness $5 \%$ was increased from 490.6 to $580.6 \mathrm{C}$. In contrast to Figure $3 \mathrm{a}$ and Figure $3 \mathrm{~b}$, we could get that the thermal stability of PI(BPDA) was better than that of PI(ODPA). This was mainly due to the fact that BPDA, a raw material for the synthesis of polyimide films, had a highly symmetrical structure and a high degree of molecular rigidity ${ }^{[23,24]}$, resulting in the improvement of molecular heat resistance. As the temperature continued to increase, the pendant groups on the main chain of the polyimide decomposed, the imine bond broke with the formation of short-chain molecules, and the benzene ring side chain dehydrogenatee to produce $\mathrm{H}_{2}, \mathrm{CO}_{2}, \mathrm{CO}^{[25]}$. With the increase of pyrolysis temperature, the quality of the film decreased obviously. Finally, the polyimide decomposed completely and the curve became stable. The quality retention rate at $800^{\circ} \mathrm{C}$ was $54.5 \%, 55.3 \%, 57.2 \%, 59.5 \%, 63.3 \%$, and $50.1 \%, 51.1 \%$, $51.5 \%, 52.2 \%, 60.1 \%$, respectively. In general, fluorinated polyimide films with different proportions of dianhydride have good thermal stability.

\subsection{Dynamic thermo-mechanical analysis of fluorinated polyimide films}

Dynamic thermo-mechanical analysis (DMA) characterizes the glass transition temperature of a material by measuring the change in the modulus of the material with temperature, that is, the manifestation of the movement of molecular chains

Table 2. The composition and name of the polyimide.

\begin{tabular}{ccc}
\hline & Dianhydride ratios & PI \\
\hline 6FDA:ODPA & $1: 9$ & PI(ODPA-1) \\
& $3: 7$ & PI(ODPA-2) \\
& $5: 5$ & PI(ODPA-3) \\
& $7: 3$ & PI(ODPA-4) \\
& $9: 1$ & PI(ODPA-5) \\
6FDA:BPDA & $1: 9$ & PI(BPDA-1) \\
& $3: 7$ & PI(BPDA-2) \\
& $5: 5$ & PI(BPDA-3) \\
& $7: 3$ & PI(BPDA-4) \\
& $9: 1$ & PI(BPDA-5) \\
\hline
\end{tabular}

and the interaction forces between molecules. The change of loss modulus (E") represented the intensity of the movement of molecular chains. The change of storage modulus( $\left.\mathrm{E}^{\prime}\right)$ represented the strength of intermolecular forces ${ }^{[26]}$. The dynamic thermo-mechanical analysis of fluorinated polyimide films were appeared in Figure 4 (take PI(ODPA-3) and PI(BPDA-3)as examples).

From the curves of loss modulus $\left(\mathrm{E}^{\prime \prime}\right)$ versus temperature in Figure $4 \mathrm{a}$ and Figure $4 \mathrm{~b}$, it could be seen that the peak temperature of the respective loss modulus represented the

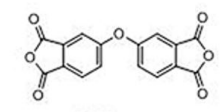

ODPA

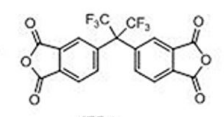

6FDA

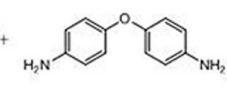

ODA<smiles>[3H][Mg]</smiles>

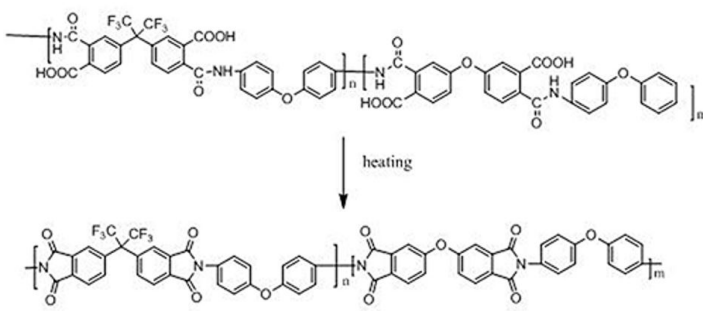

Figure 1. Polymerization reaction equation.

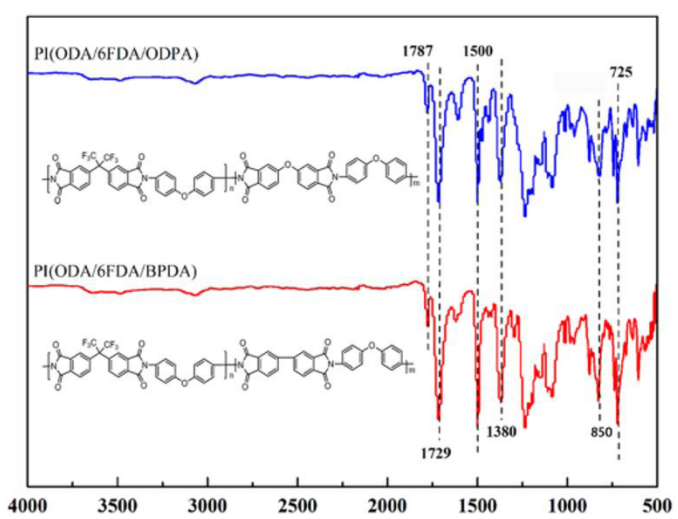

Figure 2. The infrared spectra of fluorinated copolymerized polyimide films.

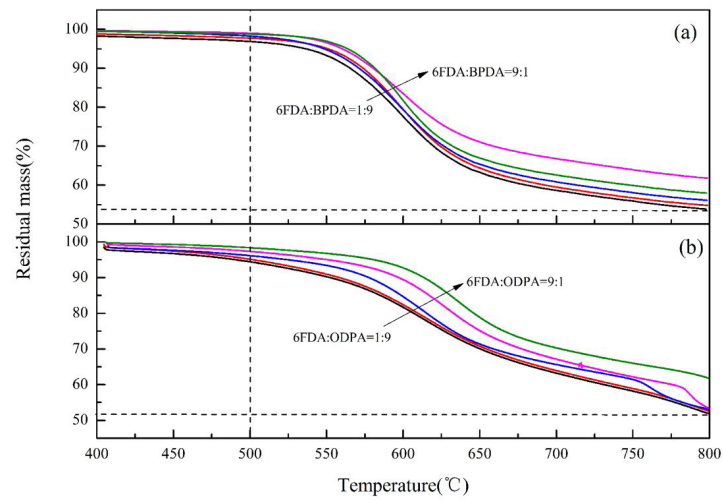

Figure 3. The thermogravimetric curves of fluorinated copolymerized polyimide films. (a) Different monomer ratio PI (6FDA/BPDA) films; (b) Different monomer ratio PI (6FDA/OPDA) films. 

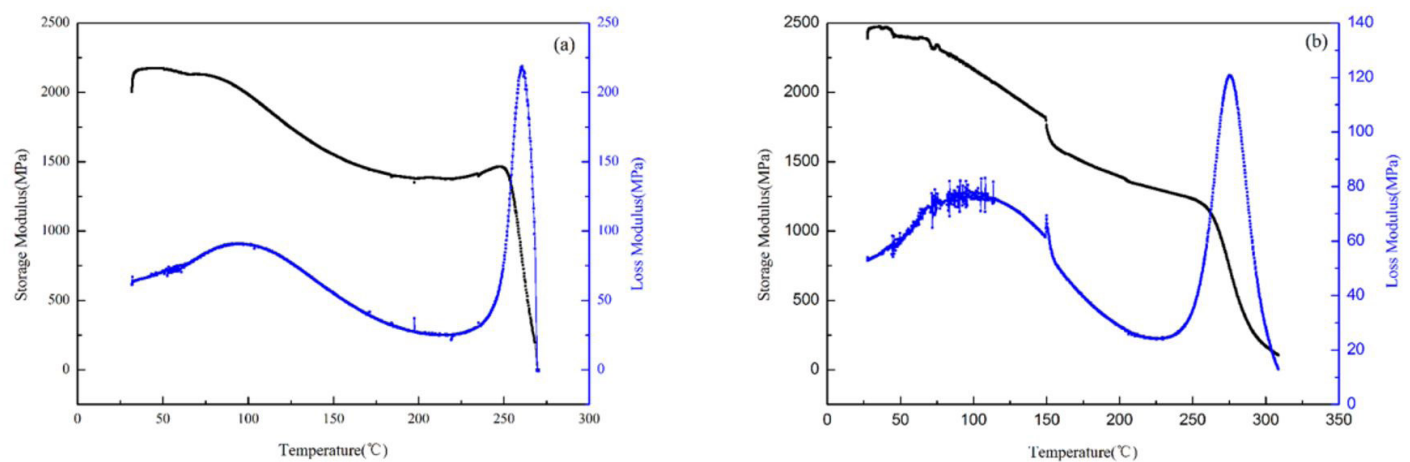

Figure 4. DMA diagram of fluorinated polyimide film. (a) Thermal performance of different monomer ratio PI (6FDA/BPDA) films; (b) Thermal performance of different monomer ratio PI (6FDA/OPDA) films.

glass transition temperature, the $\mathrm{Tg}$ of PI(ODPA-3) and PI(BPDA-3) was $260{ }^{\circ} \mathrm{C}$ and $275^{\circ} \mathrm{C}$, respectively. This was due to the existence of oxygen ether bridging bonds in ODPA, which improved the flexibility of molecular chains, resulting in a decrease in the glass transition temperature compared with BPDA. Both have glass transition temperature between $250^{\circ} \mathrm{C}$ and $280^{\circ} \mathrm{C}$, and the loss modulus reached a peak, which indicated that the material had a sharp loss of modulus in this temperature range, that is, the polymer macromolecular chain forging moved violently. At the same time, there was a close relationship between the $E^{\prime \prime}$ of the polyimide film and the molecular weight of the polymer. The larger the molecular weight of the material, the more tangles between the molecules, the displacement of molecules under external forces, and the resistance between the molecular chains, the more heat generated by friction, the greater the corresponding E". From Figure 4, we could conclude that the loss modulus(E") of PI(ODPA-3) was $218.70 \mathrm{MPa}$, and the loss modulus(E") of PI(BPDA-3) was $120.74 \mathrm{MPa}$, indicating that the existence of ODPA made the molecular chain more flexible, the molecular weight greater, and the resistance to be overcome larger.

From the curve of the storage temperature(E') change with temperature in Figure 4a and Figure 4b, the modulus at the cut-point of the storage modulus change curve was $1500 \mathrm{MPa}$ and $1250 \mathrm{MPa}$, respectively. The existence of 6FDA would make the film have more free space and the ether bond in ODA could effectively stabilize the structure and improve the tangles between the molecules. The heat generated by the film friction of ODA is higher than the film friction of BPDA.

\subsection{The mechanical properties of fluorinated polyimide films}

Figure 5 illustrated the effect of different dianhydride ratios on the mechanical properties of polyimide films.

It could be seen from Figure 5 that the tensile strength of the same series of polyimide films decreased with the increase of 6FDA ratio. The reason was that the fluorine side group existed in the 6FDA. The introduction of the side group in the polyimide chain destroyed the charge transfer complex (CTC) interaction between the polyimide chains and weakened the interaction between the molecules. Thus, the tensile strength of the polyimide film decreased

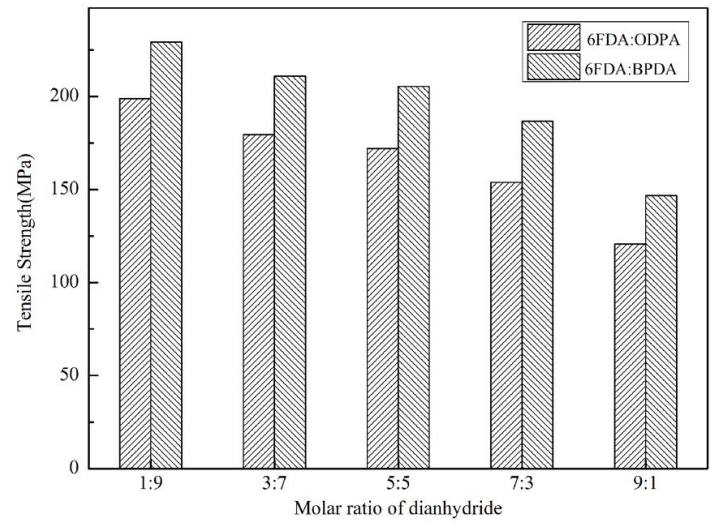

Figure 5. The mechanical properties of fluorinated polyimide films.

significantly. The tensile strength of PI(ODPA) decreased from 198.832 MPa to $120.625 \mathrm{MPa}$. The tensile strength of PI(BPDA) decreased from 229.195 MPa to $146.75 \mathrm{MPa}$. When the proportions of two dianhydrides were the same, the flexibility of polyimide molecular chain was better, the free volume increased and the rigidity of the molecular chain was reduced because of the presence of oxygen ether bridging bonds in ODPA, thus the tensile strength of the film was reduced.

\subsection{Optical properties of fluorinated polyimide films}

Traditional polyimide films were generally brown or yellow with low transparency. This was mainly due to the formation of intramolecular and intermolecular charge transfer complexes (CTCs).During the preparation of polyimide, polyamic acid were obtained by ring-opening polycondensation of the dianhydride monomer and an equal amount of the diamine monomer in the aprotic organic solvents such as DMAc and DMF. This process was accomplished through charge transfer complex (CTC) intermediates. In order to weaken the formation of CTC and obtain a highly transparent polyimide film, we use a fluorine-containing dianhydride monomer as a raw material to prepare polyimide film. Figure 6 was UV spectrogram of fluorinated polyimides. It could be seen from Figure $6 \mathrm{a}$ and $6 \mathrm{~b}$ that the transmittance of polyimide film increased with the increase of 6FDA ratio in the dianhydride. 

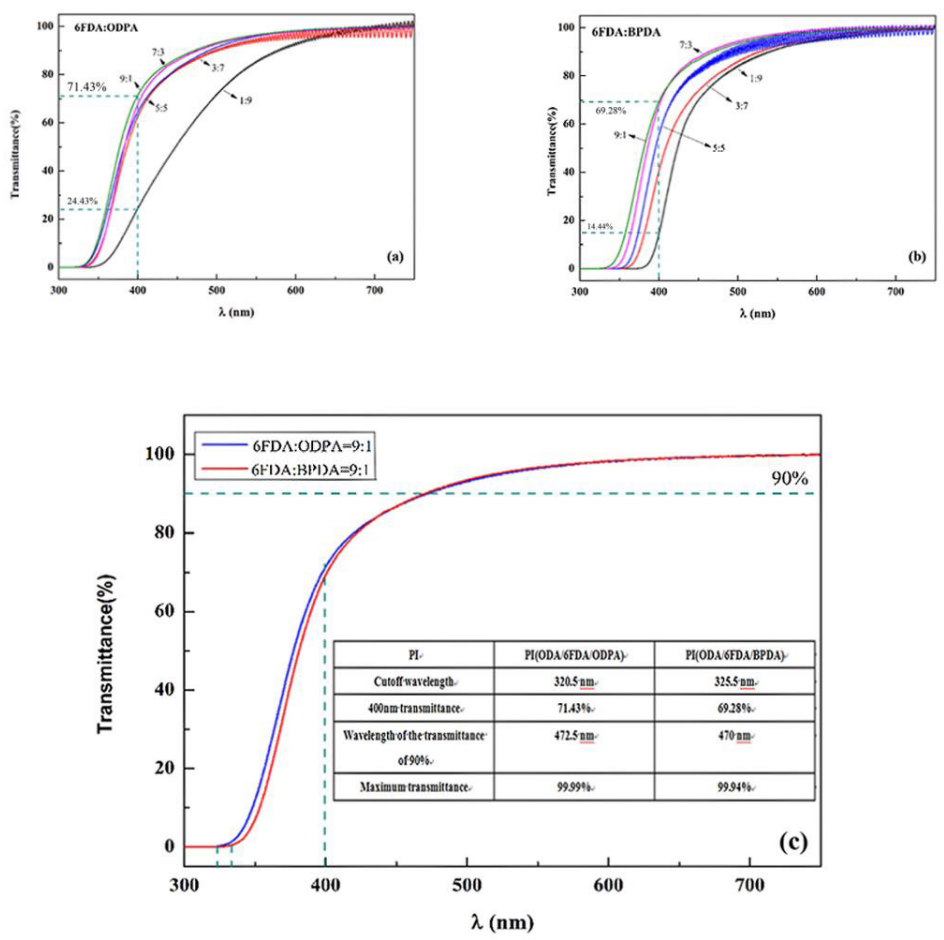

Figure 6. UV spectrogram of fluorinated polyimide films. (a) Transmittance of different monomer ratio PI (6FDA/BPDA) films; (b) Transmittance of different monomer ratio PI (6FDA/OPDA) films; (c) Formulation comparison of polyimide with optimal transparency.

When 6FDA:ODPA=1:9, the transmittance of polyimide film at a wavelength of $400 \mathrm{~nm}$ was $24.43 \%$. With the increase of 6FDA content, the transmittance of the film gradually increased. When 6FDA:ODPA=9:1, the transmittance of the film reached its maximum, its transmittance was $71.43 \%$, which was increased by 3 times. With the increase of the ratio of 6FDA to BPDA, the transmittance of the films increased from $14.44 \%$ to $69.28 \%$, and had a significant increase, which was five times higher than that of the original one. The reason for this phenomenon was that the steric hindrance effect of the bis-trifluoromethyl group in the dianhydride causes the conformation of the molecular chain to be distorted and the stacking of the molecular chains to be loose, which could effectively weaken the intermolecular forces caused by the accumulation of molecular chain $\mathrm{s}^{[27,28]}$. Therefore, the transmittance of the polyimide film has been significantly improved.

From Figure $6 \mathrm{c}$, it could be observed that the transmittance of the polyimide films at the wavelength of $400 \mathrm{~nm}$ were more than $69 \%$ and the transmittance was more than $90 \%$ at $470 \mathrm{~nm}$. Both of these films had good transparency in the UV-visible region. In contrast, PI(ODPA) had a lower cut-off wavelength and a higher transmittance at $400 \mathrm{~nm}$, indicating that the PI(ODPA) film was lighter and more transparent.

From Figure 6a, Figure 6b and Table 3, It describes that the light transmittance of the film increases with the increase of 6FDA content. The transparent of PI films which were Synthesised by 6FDA:OPDA increased from $24.43 \%$ to $71.43 \%$. The transparent of PI films which were Synthesised by 6FDA:BPDA increased from $14.45 \%$ to $69.28 \%$. The reason was that the introduction of the side group in the PI chain
Table 3. The transparent of the polyimide.

\begin{tabular}{cccc}
\hline & $\begin{array}{c}\text { Dianhydride } \\
\text { ratios }\end{array}$ & PI & $\begin{array}{c}\text { Transparent } \\
\text { of } 400 ~ \mathbf{~ m}\end{array}$ \\
\hline 6FDA:ODPA & $1: 9$ & PI(ODPA-1) & $71.43 \%$ \\
& $3: 7$ & PI(ODPA-2) & $69.02 \%$ \\
& $5: 5$ & PI(ODPA-3) & $61.27 \%$ \\
& $7: 3$ & PI(ODPA-4) & $60.58 \%$ \\
6FDA: & $9: 1$ & PI(ODPA-5) & $24.43 \%$ \\
BPDA & $1: 9$ & PI(BPDA-1) & $69.28 \%$ \\
& $3: 7$ & PI(BPDA-2) & $68.95 \%$ \\
& $5: 5$ & PI(BPDA-3) & $53.28 \%$ \\
& $7: 3$ & PI(BPDA-4) & $37.53 \%$ \\
& $9: 1$ & PI(BPDA-5) & $14.45 \%$ \\
\hline
\end{tabular}

destroyed the charge transfer complex(CTC). It was an effective way to reduce the CTC effect by weakening the intermolecular and intramolecular interactions, reducing the number of free monomers and introducing large resistance side groups. At the same time, the fluorine atoms with larger electronegativity had effectively prevented the formation of charge transfer complexes within the PI chain due to the electron-withdrawing and electron-inducing effects, further improving the optical properties of the polymer and making it exhibit good transparency ${ }^{[2,30]}$.

\section{Conclusion}

Two series of polyimides were synthesized by the two-step method from ODA and several commercial dianhydrides. The initial decomposition temperature of the films was greater than $500^{\circ} \mathrm{C}$, and the mass retention rate at $800^{\circ} \mathrm{C}$ was 
above $50 \%$, which had good thermal stability. The fluorinated Copolymer films obviously have better optical transmittance and storage modulus. Taking the 6FDA and ODPA as well as 6FDA and BPDA molar ratios of 5:5 as examples, the glass transition temperatures of the two films were $260^{\circ} \mathrm{C}$ and $275^{\circ} \mathrm{C}$, respectively. The storage modulus of the two were $1500 \mathrm{MPa}$ and $1250 \mathrm{MPa}$, respectively, and the loss modulus were $218.70 \mathrm{MPa}$ and $120.74 \mathrm{MPa}$, respectively. In the same series of fluorinated polyimide films, the tensile strength of the films decreased with the increase of $6 \mathrm{FDA}$ ratio. When the wavelength of ultraviolet light was $400 \mathrm{~nm}$, the transmittance of PI (ODPA) film increased from $24.43 \%$ to $71.43 \%$ with the increase of 6 FDA content; At the same time, the transmittance of the PI(BPDA) film increased from $14.44 \%$ to $69.28 \%$. When the wavelength was $400 \mathrm{~nm}$, the transmittance of the film was $71.43 \%$, indicating that fluorination polymerization could effectively increase the flexibility of the film, eliminate the effect of CTC, and improve the transmittance of the film. Due to the good solubility of the polyimide in the low-boiling solvent, it was possible to achieve a low-temperature curing film formation process, which lays the foundation for further widening the application of the PI film in the field of microelectronics. Therefore, this article provide a polyimide film with high transmittance(reached $71.43 \%$ at $400 \mathrm{~nm})$, high tensile strength $(218.70 \mathrm{MPa})$, high heat resistance(Half loss temperature more than $800{ }^{\circ} \mathrm{C}$ ) and high storage modulus (1500 GPa).

\section{Reference}

1. Liao, W. H., Yang, S. Y., Hsiao, S. T., Wang, Y. S., Li, S. M., Ma, C. C. M., Tien, H.-S., \& Zeng, S.-J. (2014). Effect of octa(aminophenyl) polyhedral oligomeric silsesquioxane functionalized graphene oxide on the mechanical and dielectric properties of polyimide composites. ACS Applied Materials \& Interfaces, 6(18), 15802-15812. http://dx.doi.org/10.1021/ am504342j. PMid:25153775.

2. Cheng, S.-W., Huang, T.-T., Tsai, C.-L., \& Liou, G.-S. (2017). Highly transparent polyhydroxyimide/tio2 and zro2 hybrid films with high glass transition temperature ( $\mathrm{tg}$ ) and low coefficient of thermal expansion (cte) for optoelectronic application. Journal of Materials Chemistry. C, Materials for Optical and Electronic Devices, 5(33), 5. http://dx.doi.org/10.1039/ C7TC02819A.

3. Ogura, T., Higashihara, T., \& Ueda, M. (2010). Low-CTE photosensitive polyimide based on semialicyclic poly(amic acid) and photobase generator. Journal of Polymer Science. Part A, Polymer Chemistry, 48(6), 1317-1323. http://dx.doi. org/10.1002/pola.23892.

4. Kim, B. R., Kang, J. W., Lee, K. Y., Son, J. M., \& Ko, M. J. (2007). Physical properties of low-kfilms based on the co-condensation of methyltrimethoxysilane with a bridged silsesquioxane. Journal of Materials Science, 42(12), 45914602. http://dx.doi.org/10.1007/s10853-006-0575-9.

5. Mi, Z., Liu, Z., Yao, J., Wang, C., Zhou, C., Wang, D., Zhao, X., Zhou, H., Zhang, Y., \& Chen, C. (2018). Transparent and soluble polyimide films from 1,4:3,6- dianhydro-d-mannitol based dianhydride and diamines containing aromatic and semiaromatic units: preparation, characterization, thermal and mechanical properties. Polymer Degradation \& Stability, 51, 80-89. http://dx.doi.org/10.1016/j.polymdegradstab.2018.01.006.

6. Williams, J. C., Nguyen, B. N., Mccorkle, L., Scheiman, D., Griffin, J. S., Steiner, S. A. 3rd, \& Meador, M. (2017). Highly porous, rigid-rod polyamide aerogels with superior mechanical properties and unusually high thermal conductivity. ACS Applied Materials \& Interfaces, 9(2), 1801-1809. http://dx.doi. org/10.1021/acsami.6b13100. PMid:28060486.

7. Fan, W., Zuo, L., Zhang, Y., Chen, Y., \& Liu, T. (2018). Mechanically strong polyimide / carbon nanotube composite aerogels with controllable porous structure. Composites Science and Technology, 156, 186-191. http://dx.doi.org/10.1016/j. compscitech.2017.12.034.

8. Huang, X. H., Huang, W., Liu, J. Y., Meng, L., \& Yan, D. (2012). Synthesis of highly soluble and transparent polyimides. Polymer International, 61(10), 1503-1509. http://dx.doi.org/10.1002/ pi.4235.

9. Moon, K. H., Chae, B., Kim, K. S., Lee, S. W., \& Jung, Y. M. (2019). Preparation and characterization of transparent polyimide-silica composite films using Polyimide with Carboxylic Acid Groups. Polymers, 11(3), 489. http://dx.doi. org/10.3390/polym11030489. PMid:30960474.

10. Lu, Y., Hu, Z., Wang, Y., \& Fang, Q. X. (2012). Organosoluble and light-colored fluorinated semialicyclic polyimide derived from 1,2,3,4-cyclobutanetetracarboxylic dianhydride. Journal of Applied Polymer Science, 125(2), 1371-1376. http://dx.doi. org/10.1002/app.35265.

11. Ando, S., Matsuura, T., \& Sasaki, S. (1997). Coloration of aromatic polyimides and electronic properties of their source materials. Polymer Journal, 29(1), 69-76. http://dx.doi. org/10.1295/polymj.29.69.

12. Chen, S., Yang, Z., \& Wang, F. (2019). Preparation and characterization of polyimide/ kaolinite nanocomposite films based on functionalized kaolinite. Polymer Engineering and Science, 59(s2), E380-E386. http://dx.doi.org/10.1002/ pen. 25069.

13. Huang, X. H., Pei, X. L., Wang, L. C., Mei, M., Liu, C.-J., \& Wei, C. (2016). Design and synthesis of organosoluble and transparent polyimides containing bulky substituents and noncoplanar structures. Journal of Applied Polymer Science, 133(14), 43266. http://dx.doi.org/10.1002/app.43266.

14. Yin, X., Feng, Y., Zhao, Q., Li, Y., Li, S., Dong, H., Hu, W.-P., \& Feng, W. (2018). A highly transparent, strong, and flexible fluorographene/fluorinated polyimide nanocomposite film with low dielectric constant. Journal of Materials Chemistry. C, Materials for Optical and Electronic Devices, 6(24), 63786384. http://dx.doi.org/10.1039/C8TC00998H.

15. Yang, C. P., Hsiao, S. H., \& Chen, K. H. (2002). Organosoluble and optically transparent fluorine-containing polyimides based on 4,4'-bis(4-amino -2-trifluoromethylphenoxy)-3,3',5,5'tetramethylbiphenyl. Polymer, 43(19), 5095-5104. http:// dx.doi.org/10.1016/S0032-3861(02)00359-2.

16. Wang, C. Y., Li, G., \& Jiang, J. M. (2009). Synthesis and properties of fluorinated poly(ether ketone imide)s based on a new unsymmetrical and concoplanar diamine: 3,5-dimethyl-4(4-amino-2-trifluoromethylphenoxy)-4'-aminobenzophenone. Polymer, 50(7), 1709-1716. http://dx.doi.org/10.1016/j. polymer.2009.02.006.

17. Xiao, T., Fan, X., Fan, D., \& Li, Q. (2017). High thermal conductivity and low absorptivity/ emissivity properties of transparent fluorinated polyimide films. Polymer Bulletin, 74(11), 4561-4575. http://dx.doi.org/10.1007/s00289-0171974-6.

18. Liu, L.-Z., Cao, C.-H., Ma, X.-Y., Zhang, X.-R., \& Lv, T. (2020). Thermal conductivity of polyimide/AlN and polyimide/ $(\mathrm{AlN}+\mathrm{BN})$ composite films prepared by in-situ polymerization. Journal of Macromolecular Science. Part A, 57(5), 398-407. http://dx.doi.org/10.1080/10601325.2019.1703555.

19. Shen, J., Li, F., Cao, Z., Barat, D., \& Tu, G. (2017). Light Scattering in Nanoparticle Doped Transparent Polyimide 
Substrates. ACS Applied Materials \& Interfaces, 9(17), 14990-14997. http://dx.doi.org/10.1021/acsami.7b03070. PMid:28397490.

20. Tong, Y. J., Cheng, Y. X., Ding, M. X., Xing, Y., \& Lin, Y. H. (1998). Polyimide structure-Property Relationships I. Polyimide Properties us Dianhydride Configuration. Chinese Chemical Letters, 10, 971-972.

21. Wu, G., Li, J., Wang, K., Wang, Y., Pan, C., \& Feng, A. (2017). In situ synthesis and preparation of $\mathrm{TiO} 2 /$ polyimide composite containing phenolphthalein functional group. Journal of Materials Science Materials in Electronics, 28(9), 6544-6551. http://dx.doi.org/10.1007/s10854-017-6343-6.

22. Wu, G., Cheng, Y., Wang, Z., Wang, K., \& Feng, A. (2017). In situ polymerization of modified graphene/polyimide composite with improved mechanical and thermal properties. Journal of Materials Science Materials in Electronics, 28(1), 576-581. http://dx.doi.org/10.1007/s10854-016-5560-8.

23. Purushothaman, R., Bilal, I. M., \& Palanichamy, M. (2011). Effect of chemical structure of aromatic dianhydrides on the thermal, mechanical and electrical properties of their terpolyimides with 4,4'-oxydianiline. Journal of Polymer Research, 18(6), 1597-1604. http://dx.doi.org/10.1007/s10965-011-9564-z.

24. Eichstadt, A. E., Ward, T. C., Bagwell, M. D., Farr, I. V., Dunson, D. L., \& Mcgrath, J. E. (2002). Structure-property relationships for a series of amorphous partially aliphatic polyimides. Journal of Polymer Science. Part B, Polymer Physics, 40(14), 1503-1512. http://dx.doi.org/10.1002/polb.10210.

25. Liu, H., Zhai, L., Bai, L., He, M., Wang, C., Mo, S., \& Fan, L. (2019). Synthesis and characterization of optically transparent semi-aromatic polyimide films with low fluorine content. Polymer, 163(1), 106-114. http://dx.doi.org/10.1016/j. polymer.2018.12.045.

26. Li, Z., Kou, K., Zhang, J., Zhang, Y., Wang, Y., \& Pan, C. (2017). Solubility, electrochemical behavior and thermal stability of polyimides synthesized from 1,3,5-triazine-based diamine. Journal of Materials Science Materials in Electronics, 28(8), 6079-6087. http://dx.doi.org/10.1007/s10854-016-6284-5.

27. Wang, C., Cao, S., Chen, W., Xu, C., Zhao, X., Li, J., \& Ren, Q. (2017). Synthesis and properties of fluorinated polyimides with multi-bulky pendant groups. RSC Advances, 7(42), 2642026427. http://dx.doi.org/10.1039/C7RA01568B.

28. Kim, M. K., Hwang, S. H., Jung, H. S., Oh, T. S., Kim, J. H., \& Yoo, J. B. (2018). Inkjet Printing of $\mathrm{SiO} 2$ Hollow Spheres/Polyimide Hybrid Films for Foldable Low-k ILD. Macromolecular Research, 26(12), 1123-1128. http://dx.doi. org/10.1007/s13233-019-7001-z.

29. Yang, C. Y., Hsu, L. C., \& Chen, J. S. (2005). Synthesis and properties of 6fda-bisaaf-ppd copolyimides for microelectronic applications. Journal of Applied Polymer Science, 98(5), 20642069. http://dx.doi.org/10.1002/app.22410.

30. Chang, H. C., Byung, H. S., \& Chang, J. (2013). Colorless and transparent polyimide nanocomposites: comparison of the properties of homo- and copolymers. Journal of Industrial and Engineering Chemistry, 19(5), 1593-1599. http://dx.doi. org/10.1016/j.jiec.2013.01.028.

Received: Feb. 11, 2020

Revised: Apr. 21, 2020

Accepted: June 20, 2020 